\title{
ETA-II Experiments for Determining Advanced Radiographic Capabilities of Induction Linacs
}

\author{
J. T. Weir, G. J. Caporaso, J. C. Clark, H. C. Kirbie, Y.-J. Chen, \\ S. M. Lund, G. A. Westenskow and A. C. Paul
}

This paper was prepared for submittal to the 1997 Particle Accelerator Conference

Vancouver, B. C., Canada

May 12-16, 1997

May 1997

This is a preprint of a paper intended for publication in a journal or proceedings. Since changes may be made before publication, this preprint is made available with the understanding that it will not be cited or reproduced without the permission of the author. 


\section{DISCLAIMER}

This document was prepared as an account of work sponsored by an agency of the United States Government. Neither the United States Government nor the University of California nor any of their employees, makes any warranty, express or implied, or assumes any legal liability or responsibility for the accuracy, completeness, or usefulness of any information, apparatus, product, or process

disclosed, or represents that its use would not infringe privately owned rights. Reference herein to any specific commercial product, process, or service by trade name, trademark, manufacturer, or otherwise, does not necessarily constitute or imply its endorsement, recommendation, or favoring by the United States Government or the University of California. The views and opinions of authors expressed herein do not necessarily state or reflect those of the United States Government or the University of California, and shall not be used for advertising or product endorsement purposes. 


\title{
ETA II Experiments for Determining Advanced Radiographic Capabilities of Induction Linacs
}

\author{
J. T. Weir, G. J. Caporaso, J. C. Clark, H. C. Kirbie, Y.-J. Chen, S. M. Lund, G. A. Westenskow \\ and A. C. Paul \\ Lawrence Livermore National Laboratory
}

- Abstract

- LLNL has proposed a multi- pulsed, multi-line of sight radiographic machine based on induction linac technology to be the core of the advanced hydrotest facility (AHF) being considered by the Department of Energy. In order to test the new technologies being developed for AHF we have recommissioned the Experimental Test Accelerator (ETA II). We will conduct our initial experiments using kickers and large angle bending optics at the ETA II facility. Our current status and our proposed experimental schedule will be presented.

\section{INTRODUCTION}

LLNL has proposed using induction linac technology as the driver for the AHF system being considered by the Department of Energy. The concept includes building a long pulse accelerator (200 ns.) and using a stripline beam kicker and septum magnet system to chop the long pulse into shorter pulses (50 ns.) The pulsed kicker will induce a small angular difference between the front and the back of the beam before it runs through the septum magnet. The septum magnet is a dc magnetic field designed with the left half of the field oriented up and the right half oriented down. This septum greatly magnifies the angular differences between the two pulses which will be routed to separate beam lines. (Figure 1) By repeating the process the two beams can become four beams which will converge on the target area and give four lines of sight in the radiographic chamber. High beam quality (low emittance) must be maintained during the chopping and transporting of the pulses. To validate the kicker and transport technology, experiments are needed, measuring the effects on beam quality of a kicker and a large angle transport beam line. We have chosen to resurrect the Experimental Test Accelerator (ETA II) as the test bed for these validation experiments.

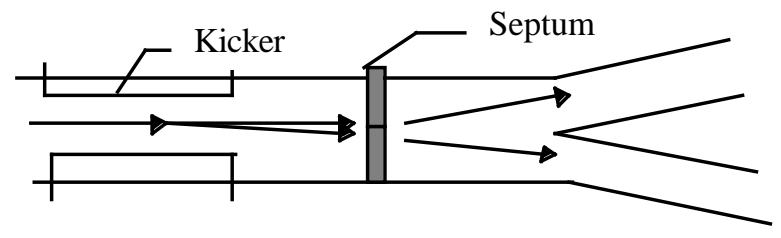

Figure 1

\section{THE ACCELERATOR}

ETA II is a linear induction accelerator that was designed to accelerate electrons for use as the driver in a free electron laser experiment. The facility was shut down in 1992 with various components being scavenged for other projects. In the Spring of 1996, we began looking at ETA II as a possible test bed for the AHF experiments. On the negative side was the fact the system had not been run for more than four years, many of the components were missing and many of the remaining subsystems were in disrepair. The advantage of resurrecting ETA II was in having a dedicated system that would permit precision measurements of kickers and transport lines. The ETA II parameters were well known and would scale easily to an AHF system. (Table 1) By the summer of 1996 it was decided to resurrect ETA II and the work began.

ETA II Accelerator Parameters

$\begin{array}{ll}\text { Energy } & 6.3 \mathrm{MeV} . . \\ \text { Current } & 2 \mathrm{kA} . \\ \text { Pulse Width } & 60 \mathrm{~ns} . \\ \text { Energy } & +/-1 \% \\ \text { Regulation } & \\ \text { Repetition } & 1 \mathrm{~Hz} . \\ \text { Rate } & \end{array}$

Table 1

The injector and each of the sixty accelerating cells were disassembled and fitted with new O-rings and vacuum seals. The high voltage insulators were cleaned or replaced and vacuum and fluid system were overhauled. Missing vacuum pumps and valves were recalled from other programs and missing equipment was replaced.

Each of the four pulse power units (MAGS) was completely disassembled and rebuilt and the power supplies for the solenoid magnets and steering magnets were brought back on line.

In the control room, we brought up the computers for the safety system, the mechanical system, the pulse power and magnetic control systems and the data acquisition and analysis system. In many cases we had to restore the programs from archived backup tapes as the original could not be located or would not execute.

By December of 1996 we had the injector running and by April of 1997 we had the full accelerator running at $2 \mathrm{kA}$. and $6.2 \mathrm{MeV}$.

In order to compare the refurbished accelerator with its past performance an emittance measurement was made at 
the $2.5 \mathrm{MeV}$. point (after the first 20 cells) using a pepper pot emittance diagnostic. The pepper pot mask was drilled with a pattern of $0.0568 \mathrm{~cm}$. diameter holes and was $86.85 \mathrm{~cm}$. from the phosphor coated viewing plate. An emittance of $17 \mathrm{~cm}$.-mrad. (uncorrected for space charge) was measured with a beam current of 1700 amps. This corresponds to a whole beam brightness of $3 \times 10^{8}$ $\mathrm{A}(\mathrm{m}-\mathrm{rad})^{2}$ which is the same value measured after 20 cells in 1990 .

After we achieved full power operation of the accelerator and measured the emittance, we began the installation of the first experimental beam line.

\section{THE EXPERIMENTAL BEAM LINE}

We are currently building the first of our experimental beam lines. The purpose of these first experiments will be to measure the quality of the beam before and after our preliminary kicker design. The beam line will be laid out as one continuous straight section with no splitting of the beam line after the septum. After the end of the accelerator, the beam is transported by discrete solenoids through an energy analyzer, a solenoidal emittance selector, a final focusing magnet, the kicker, the septum, and finally to the pepper pot emittance diagnostic.(Figure 2) In this initial experiment we will use a static dipole magnetic field over the kicker and by choosing the polarity of the dipole field and the applied voltage to the kicker we can select either section of the chopped beam to be directed into the diagnostic beam line.

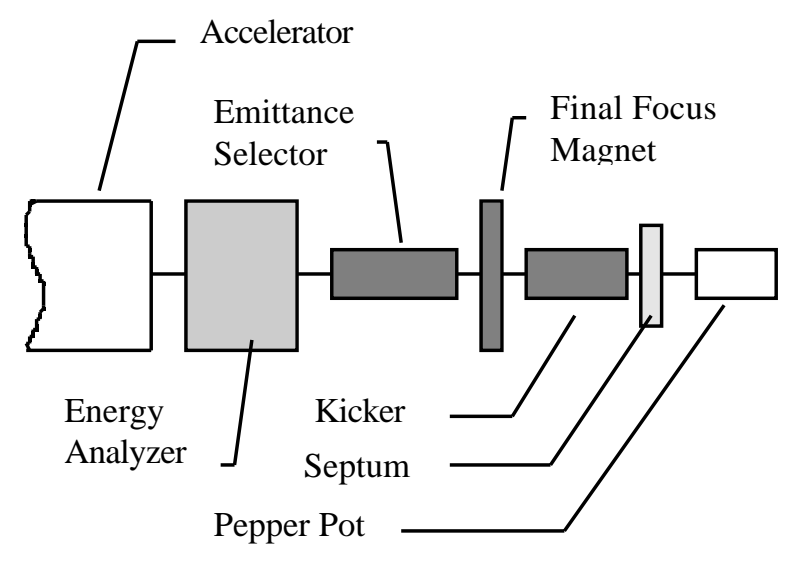

Figure 2

\section{THE INITAIL EXPERIMENTS}

Our initial experiments should begin in June of 1997. We will begin by measuring the quality of the beam delivered to the experimental section. Energy measurements will be taken and the timing of the accelerator cells will be adjusted until we have less than $1 \%$ energy variation across the central $40 \mathrm{~ns}$. of the beam. Maintaining a minimum energy sweep prevents the build up of the corkscrew motion of the beam through the accelerator which can lead to degraded emittance. Energy variations of less than $1 \%$ were recorded on ETA II before it was shut down in 1992.

After the energy tests, we will run the beam through the solenoidal emittance selector. In addition measuring the whole beam brightness, the emittance selector will be used as a knob on the current entering the kicker section. Changing the current in the accelerator requires retuning the accelerator and this can be a time consuming task. We will run the accelerator at a standard current $(2 \mathrm{kA}$.) and then use the emittance selector to adjust the current to the experimental section.

Next, we will transport the beam to the pepper pot diagnostic for a detailed emittance measurement. For these measurements the kicker and the septum magnet will be replaced with blank section of beam pipe. This will give us the baseline performance of the beam.

At this point we will install the kicker system without the septum magnet. We will run a series of tests on the kicker in an un-powered mode. We need to measure the effects of beam induced voltages on the kicker rods as a function of beam current and beam centroid offset. The primary diagnostic for this set of experiments will be the beam current and position monitors down stream of the kicker. We will also repeat the emittance measurement to ensure we have not degraded the beam quality.

Next we will begin running the high voltage pulser (9 $\mathrm{kV}$.) to the kicker deflection rods. Issues we need to investigate include reflections of the power pulses back to the pulser and possible emittance growth in the kicked beam.

Our final set of experiments in this configuration will involve installing the septum magnet and measuring the effect of the septum's field on the beam emittance.

Once we have successfullly tested the preliminary kicker/septum design we will use the data we collect to modify the design as necessary and begin the construction of our next beam line.

\section{FUTURE EXPERIMENTS}

Another key technology we will study using the ETA II test bed will be the issue of beam transport. In order for the long pulse technology to work we must be able to route the pulses through long transport lines involving bends as large as 90 degrees. This transport must be done without degrading the beam quality if the radiographic spot size is to be kept small. We will begin our transport studies by removing the kicker/septum section of our beam line and replacing it with a 30 degree bend on classical magnetic transport. We will then measure the quality of our beam after this bend. These experiments should begin by December of 1997 . If the magnetic transport is shown to be successful we will replace the magnets with the kicker/septum system and repeat the transport experiments. These experiments should begin in the spring of 1998 and will use a modified 
kicker/septum system that has been designed with the data from our earlier experiments.

Our final transport experiment would be to construct a beam line with a pair of kickers and a 90 degree bend. This beam line would address most of the key issues associated with the LLNL long pulse proposal for AHF. Proving our ability to use multiple kickers and transport the beam through large angle bends without degrading the beam quality would be a large step towards implementing the long pulse AHF technology.

In addition to the kicker and transport issues we will study, LLNL is working on the pulsed power and advanced cell design that will be necessary to create a long pulse induction linac. When the pulsed power modules and test cell have completed their laboratory testing they will be brought to ETA and installed in our beam line. Operating the test cell with the advanced pulsed power system in the actual accelerator environment will be a final demonstration for these key elements.

\section{CONCLUSIONS}

We have brought the ETA II accelerator out of mothballs and tested it at full current and voltage. The beam quality has been measured and it is identical with the high quality beam that was being produced before the accelerator was shut down. ETA II is ready to be the test bed for the kicker and transport experiments necessary to validate the LLNL long pulse proposal for the AHF accelerator. We are installing our first beam line now and should begin our experiments in June of 1997.

\section{ACKNOWLEDGMENTS}

The work was performed under the auspices of the U.S. Department of Energy by the Lawrence Livermore National Laboratory under contract W-7405-ENG-48. 


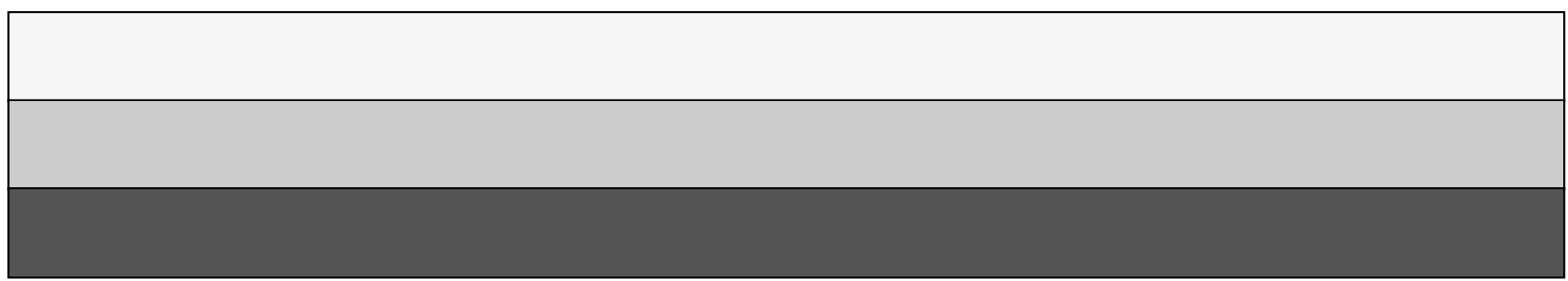

